\title{
Integration of HIV and AIDS in Higher Education Curriculum: A Case Study of an HIV Course in the School of Education of the University of Zambia
}

\author{
Harrison Daka*, Kapambwe Mwelwa, Pilira Chirwa-Tembo, Mukuka Mulenga-Hagane \\ Department of Educational Administration and Policy Studies, University of Zambia, Lusaka, Zambia \\ *Corresponding Author: Harrison Daka, Department of Educational Administration and Policy Studies, \\ University of Zambia, Lusaka, Zambia
}

\begin{abstract}
HIV and AIDS challenge the human ethical and moral foundations likeno disease has ever done. It is undoubtedly one of the major catastrophes of our time, especially in Africa. The disease has tragic consequences for the social, economic and political life.The AIDS pandemichas affected every aspect of Zambian society and is recognized as the greatest public health challenge in the last four decades. Nevertheless, education can generate hope in the face of the epidemic using different methods, including integration of HIV and AIDS issues in the school curriculum. This article illustrates how the integration of HIV and AIDS into the curriculum in tertiary level of education has contributed to the reduction of the spread and has changed the perception of students and staff about the epidemic. In this study data were collected using a questionnaire survey of 200 students who took the HIV and AIDS Course, and three case stories from amongst these students in the School of Education at University of Zambia. During the course of the study, School of Education had been offering the 'HIV and AIDS Issues in Education' course from 2010. Findings showed that most knowledge, attitudes and opinions of participants changed positively from before they did the course to after doing the course. The three case stories indicated that the course they did positively affected their lifestyles and actions taken.
\end{abstract}

Keywords: Curriculum, Integration, HIV Education

\section{INTRODUCTION}

Many countries have faced up to the systemic impact of HIV on education and are doing something about it. But currently the objective of these interventions is to ensure that education systems can continue to function - essentially that they can continue their education business as usual. Undoubtedly, much energy has been spent on the curriculum and the integration of content relevant to the AIDS epidemic. But to what extent has this been little more than curriculum tinkering, the consideration of an almost infinite variety of models, but no real fundamental examination of the kind of education needed in a world with AIDS?

There has been less concern, however, with the whole purpose and rationale of a school curriculum and what the schools (and other channels for the provision of education) should be trying to achieve in the face of the AIDS epidemic. Education and training are critical long term and sustainable development interventions and are directly linked to positive economic development, emancipation and health dividends. The HIV and AIDS epidemic has however negatively impacted the education sector at local, district, provincial and national level, affecting the demand for education; the supply of education; and the quality and management of education.

Neither words nor statistics can adequately capture the human tragedy of children grieving for dying or dead parents, stigmatized by society through association with AIDS, plunged into economic crisis and insecurity by their parents' death and struggling without services or support systems in impoverished communities. According to United Nations AIDS (UNAIDS) and the World Health Organisation (WHO), Deaths related to HIV and AIDS in Zambia was 10,000 in 1990 and 20,000 in 2007. In 2008, 1,250,000 people were reported to be infected with HIV (Chilangwa, 2010).

\subsection{Importance of Training Institutions}

History has placed a great burden on the shoulders of educators in Zambia. Kelly (2008) highlighted that as members of the human race and as educators, every one of us here today faces a task that has 
ramifications for the lives and well-being of countless individuals-adults, youth, and children (Mwelwa, et al., 2018). Each of us bears the lives of others in our hands. Therefore, education can play a role in mitigation of HIV spread. When looking at the formal education sector, several questions come to mind. Does being educated make it less likely that a person will contract HIV or does it make it more likely? If there is to be teaching about preventing the transmission of HIV and about sexual and reproductive health, what can be done to support and empower teachers to play their part? In answering these questions, integration of HIV and AIDS in the curriculum will need to put all such issues into consideration.The population of young people in learning institutions is very high such that if the policies are formulated to target interventions in such settings, the fight against the spread of HIV can be significant. Tables 1 below show the population of students in higher learning institutions in Zambia

Table1: Number of Students in Higher Education, 2012

\begin{tabular}{|l|c|}
\hline Type of Higher Education Institution & Number of Students \\
\hline In Colleges & 7,496 \\
\hline In University & 24,525 \\
\hline
\end{tabular}

Source: MOE (2012). We have to include latest statistics here, to amplify

\subsection{Importance of Integrating HIV and AIDS in Higher Education Curriculum}

Coombe and Kelly (2001) reported that universities in Africa are high-risk institutions for transmission of HIV. This situation is caused by several factors, including the "sugar daddy" practice (having sex with older men for socioeconomic gain), sexual experimentation, prostitution on campus, unprotected casual sex, gender violence, multiple concurrent partners, and similar HIV high-risk activities that contribute to a greater or lesser degree, to the transmission of the infection (Daka, et al., 2017). Furthermore, universities are commonly located in large and/or capital cities where the prevalence of HIV tends to be highest.

For instance, the University of Zambia (UNZA), where the study was conducted is located in Lusaka, the capital city of Zambia, a Sub-Saharan region that has the highest HIV sero-prevalence in the world (UNAIDS, 2013a, 2013b). According to the 2013 - 2014 Zambia Demographic and Health Survey (ZDHS), HIV prevalence in Zambia was $13 \%$ in the 15-47-year-old age group, while the urban prevalence in Lusaka was $16.3 \%$ (ZDHS, 2016). In 2014, the university of Zambia had a total population of 15,500 people. This consisted of 12,750 undergraduate students $(8,000$ attending full time and 4,750 attending by distance education), 250 postgraduates, 2,000 support andtechnical staff, and 500 academic staff (Daka, et al., 2017). At the beginning of the AIDS epidemic in the 1980s and 1990s, UNZA health services offered limited HIV and AIDS interventions. Although $76.1 \%$ of UNZA students were aware of HIV and AIDS, over half of them (53.9\%) reported that they had participated in unprotected vaginal sex, $3.0 \%$ in anal sex, and $20.9 \%$ either anal or oral sex. Having multiple sexual partners was common (Malungo, 2006). From these statistics it is obvious that has practical but aggressive forms of fighting HIV and AIDS were needed in learning institutions.

\subsection{The Need for Integrating HIV and AIDS into the Curriculum}

Most of the nations and the churches in particular, have worked hard to provide education so that it could help them curb the spread of HIV/AIDS. Unfortunately poverty, illiteracy and ignorance have taken the greatest share on the challenges faced (Moerschbacher, etal., 2008). For the HIV and AIDS to be fought effectively, there is need to include AIDS issues in the school curriculum. This is so because it is only education that can uproot some deep-rooted cultural beliefs of the different groupings of people which continue to perpetuate the spread of HIV. The principle message of HIV has been summed up in the ABC slogan. Where the letters; A stands for Abstinence, B for be faithful, and $\mathrm{C}$ for Condom. But unfortunately, while the slogan may be simple to remember, its practice has been less easy to uphold for a variety of practical and cultural reasons (Mukuka and Daka, 2018). As such there is need to learn how to put the principle massage into correct practice. Parents continue to play a minimal role in providing these skills to their children (Daka, 2017). Parents have been seen as the main hindrance, since they are not willing, due to cultural beliefs to take up the responsibility of educating the youths in sexual matters. Nyondo (2013:9) further asserts that "addressing the challenges young people are facing means that certain cultural beliefs which curtail parents from 
discussing sexual matters with their children should be discarded". Richards (2002) adds that, the only hope for the entire world is prevention through educational efforts, new forms of prevention, and the development of a vaccine. While the pharmaceutical scientists are searching for the latter, progress should be made within the former.

Sahu (2004) argue that different strategies are being adopted for young people among which the school AIDS education is very important. The argument is that youths are among the most vulnerable groups to HIV infection because they are too young to go for permanent relationships and that they are more likely going to have unsafe sex since the act is done in complete secrecy and mostly in an unplanned manner. In most cases, the sexual activity for the youths is merely a game where they could be changing sex partners quite frequently, thus exposing themselves to HIV and other sexually transmitted infections (Mukuka and Daka, 2018). They are highly impressionable and require appropriate information about reproductive issues including safe sex behaviour. It is therefore beneficial to educate the young about the process of growing up and its implications. Mbulo(2014:19) quote Sibusenga arguingthat "HIV and AIDS among youths is a risk to Zambia's development and burden of the economy, national security and as all that goes into the nation lies in the youth".

If the youth became bedridden, then we are in trouble. Assuch it is hoped that this education on sexual and reproductive health will enable the children to develop in a stable value system and adopt responsible life styles(Bonjour \& Van Der Vlugt, 2018). Young people once given the AIDS education can also be agents of change and spearhead advocacy for AIDS education among peers especially in developing countries where universal education is yet to be achieved. The aim of including AIDS education in the curriculum in Higher Educationis to encourage and develop life skills which may help the young people in making correct choices in life. The conclusion from the above deliberation is quite obvious; there is a dire need to include AIDS education in the curriculum in schools so that the largest population is captured and taught in good morals that will help them survive in the AIDS era while they are at a tender age.

Most current HIV and AIDS programmes are often restricted to the passive dissemination of information through posters, media and display of sex billboards in the streets and behind the automobiles. Such kinds of programmes are limited to urban areas and well up to do communities and the privileged few whose literacy levels are high enough tocomprehendthe massages that are being communicated. More aggressive efforts are therefore needed to reach out to each and every rural community throughout the country, to combat the spread of this disease. The only way such communities can be reached is through education of the young who are elders of tomorrow and in this all the people can receive this life saving massage. One of the ways through which this can be achieved is the integration of Comprehensive Sexuality Education in the Curriculum.

\subsection{Comprehensive Sexuality Education}

Comprehensive Sexuality Education (CSE), also known as sexuality education is defined as ageappropriate, cultural relevant approach to teaching about sex and relationships by providing scientifically accurate, realistic and non-judgemental information (UNESCO, 2009:2). The integration of comprehensive sexuality education in the mainstream curriculum has been one of the ways many governments are fighting the scourge of HIV and AIDS, Zambia inclusive. Education thus is used as a social vaccine to fight the pandemic. Bojour and Van der Vlugt (2018) put it that CSE is associated with empowerment, gender equality, and a rights based approach which puts young people at the centre of educational provision. According to Panchaud (2019:278) the ultimate goal of this integration is "to impart in young ones with life skills such as self-confidence, assertiveness, selfesteem so as to strengthen their decision making and communication skills".

Literature shows that exposure of learners to effective sexuality education leads to reduced exposure to pre-marital sex, transmission of HIV and AIDS, unwanted pregnancies and school drop-out rates (Bonjour \& Van der Vlugt, 2018). Admittedly, it can be argued that unlike other subjects in school, Comprehensive Sexuality Education exposes students to experiential learning. Learners are thus offered opportunities to take initiatives and make wise decisions about their lives. It helps them to be exposed to different opportunities to express themselves intellectually, physically, emotionally and sexually. According to UNESCO (2009:6) the transfer of knowledge about HIV transmission remains 
low in most countries and as such schools have been identified as the most appropriate avenue for breaking this barrier. Therefore, those being trained as teachers today, present an opportunity for young people to receive accurate and comprehensive knowledge about HIV and AIDS and how it can be prevented. With knowledge and skills about Sexual and Reproductive Health, those trained to be teachers are empowered not only to protect themselves but also their learners by sharing information about sexuality appropriately. Thus learners in schools are exposed to relevant teaching and learning interventions which are scientifically and culturally acceptable.

Due to the influence of culture and religion as discussed elsewhere in this paper, Comprehensive Sexuality Education in schools is the only opportunity which provides an avenue of exposing young people to age-appropriate, culturally and scientifically appropriate information to help them make the right decisions about their sexuality, develop health relationships and avoid risk behaviour. There is therefore a convincing rationale for the introduction of Comprehensive Sexuality education in the curriculum. This is evidenced by the three case stories presented in this study which demonstrates how the spread of HIV and AIDS, other sexually transmitted diseases, unwanted teen pregnancies, and risk-sexual behaviour can be reduced if both teachers and learners were exposed to sexual and reproductive health education. Exposure to this knowledge reduces young peoples' vulnerability and exposure to HIV and AIDS (UNESCO, 2009).

The primary goal of sexuality education as an intervention in the fight against the HIV pandemic and other social ills is to equip learners with the most appropriate knowledge and skills to make responsible choices about their sexual and reproductive health. This is cardinal especially in Zambia where the spread of HIV and AIDS and prevalence rate remains high (GRZ, 2014). While evidence on the effectiveness of comprehensive sexuality education in Zambia may be scarce and complex to adduce, there are a number of studies which point to the effectiveness of these programmes in the education sector.

For instance, a study by Prachaud et al. (2019) found that many countries both within and outside Africa have integrated CSE in the school curriculum. Some of the African countries included Ghana, Kenya and South Africa to name a few. The integration of comprehensive sexuality education in the curriculum is said to have led to behavioural change in many school going young adults who seem to be more susceptible to the scourge of HIV transmission and other STIs. Another study commission by UNESCO (Vinogradova, 2014) on the importance of comprehensive sexuality education collected data from young adults aged between 10 and 24 in Zambian schools. Focussing on the quality of sexuality education in schools, by looking at sexual and reproductive health, sexual harassment and discrimination of those infected by HIV and AIDS, the study found that some aspects of comprehensive sexuality education were effectively communicated to the learners and thus resulted in risk reduction behaviour. As a baseline study in Zambia, this study provided valuable information on different aspects of sexual and reproductive health, attitudes and experiences of the young people.

Another study by Vanwesenbeecketal. (2016) evaluated the lessons learnt from the implementation of comprehensive sexuality education in developing countries with half of the population being younger than 25 years old. From their findings, they argued that effective provision of comprehensive sexuality education promoted quality sexuality knowledge, effective communication skills and attitudes amongst the young people. For instance in Uganda, the study (Vanwedenbeeck, etal. 2016:475) found that knowledge of the young people about sexual reproduction health and nonabusive relationships increased. In addition, the self-reported interviews and focus group discussions with the youths aged between 15 and 17 years showed that comprehensive sexuality education was effective on some aspects of their sexuality.

To signify the relevance of Comprehensive Sexuality Education in a country, where more than half of the total population are youths (MOESVEE, 2013) the Ministry of Education has integrated Sexuality education in the school curriculum. Apart from introducing CSE in the primary and secondary school curriculum, the government of the Republic of Zambia has also integrated the issues of HIV and AIDS in teacher education to prepare those who are supposed to teach the young ones. The University of Zambia, through the School of Education, offers education courses which encompass comprehensive sexuality education in teacher education curriculum. The rationale for providing such cross-cutting issues in the teacher education curriculum is to equip students with the knowledge about 
HIV/AIDS and sexual reproductive health. It is believed, this knowledge is likely to help the wouldbe teachers to teach sexuality education in school without religious and socio-cultural interference.

At tertiary level, sexuality education is also offered as a crossing cutting issue embedded in various courses. In some cases sexuality education is offered within courses such as the HIV and AIDS Issues in Education which is being referred to in this article. Student teachers who eventually become teachers continue to be exposed to sexuality education at that level in order to equip them with content and pedagogy on how they can teach sexuality education in secondary schools. Apart from protecting themselves from the scourge of HIV and AIDS, the student teacher become role models later in their teaching career as they transfer knowledge and skills about sexual and reproductive health to those young ones they teach. This makes learning about sexuality education become a shared responsibility between teachers and parents.

The school curriculum therefore encompasses a number of cross-cutting issues which are essential for the wellbeing of society. These cross - cutting include life skills, gender, human rights, HIV/AIDS and Sexual Reproductive Health which fall under Comprehensive Sexuality Education (MOESVTEE, 2013). In Zambia therefore, comprehensive has been used as a public health strategy to combat HIV/AIDS and unwanted teen pregnancies. The goals of CSE in the teacher education curriculum are to bring about sexually desirable attitudes, practices and personal conducts on the part of adolescents and young adults. With this knowledge, it is believed that individuals can be protected as humans and families as social institutions from the HIV pandemic. Having highlighted the importance of integrating sexuality education in the curriculum, the subsequent section details the methodology used in the study.

\section{Methodology}

\subsection{Participants}

The questionnaire was administered to 100 fourth year students (not taking an HIV and AIDS course) and 100 fourth year students (enrolled in the "Introduction to HIV and AIDS Issues in Education" course) School of Education UNZA students (Table 1.1). Thestudy was conducted towards the end of the course, after participants hadlearned concepts related to HIV and AIDS and the important role educationplays in the national response to the epidemic. The three (3) case stories were recorded from two final year students (one male and one female) and one who had already graduated (female). This was done in order to get various views from students at different level and experiences.Consent was obtained for participation and six students declined. This gave us a response rate of $98 \%$.

Table2: Demographic Characteristics of Survey Participants

\begin{tabular}{|c|c|c|c|c|c|c|}
\hline & \multicolumn{2}{|c|}{ Students not taking HIV Course } & \multicolumn{2}{|c|}{ Students taking HIV Course } & \multicolumn{2}{|c|}{ Total Students } \\
\hline & Frequency & Percentage & Frequency & Percentage & Frequency & Percentage \\
\hline \multicolumn{7}{|l|}{ Gender } \\
\hline Female & 56 & 57.1 & 58 & 60.4 & 114 & 58.8 \\
\hline Male & 42 & 42.9 & 38 & 39.6 & 80 & 41.2 \\
\hline Total & 98 & 100 & 96 & 100 & 194 & 100 \\
\hline \multicolumn{7}{|l|}{ Age } \\
\hline Below 20 & 19 & 19.4 & 00 & 0.0 & 19 & 9.8 \\
\hline $20-24$ & 67 & 68.4 & 82 & 81.2 & 149 & 76.8 \\
\hline Above 25 & 12 & 12.2 & 18 & 18.8 & 30 & 15.4 \\
\hline
\end{tabular}

\subsection{Ethical Issues and Institutional Review Board Approval}

The research was on HIV and AIDS and this is mostly resisted by most people to participate in. So some resistance was encountered, especially when giving the questionnaires to randomly sampled students. The study was approved by the Institutional Review Board of UNZA, through the Department of Educational Administration and Policy Studies.

\subsection{Analysis}

Data analysis used both quantitative and qualitative methods of analysis. Participants views on the knowledge and attitudes were compared with each other between those in first year (before doing the course) with the views of the fourth years (those who did the course). Analysis was completed after 
surveys were collected from participants and the data was fully cleaned and coded for trends, patterns, and anomalies. Quantitative data was organized using Excel and SPSS software. The data from the case stories were recorded as such and their views were analysed.

\section{FINDINGS AND DISCUSSION}

The composition of the first year respondents was $42.9 \%$ male and $57.1 \%$ female while for forth year respondents, $39.6 \%$ were male and $60.4 \%$ were female. Most of the respondents $(84.6 \%)$ were of young age (below 25 years) and $15.4 \%$ were 25 years and above.

\subsection{Knowledge level about HIV and AIDS}

While 93.8 percent of the respondents knew that there was no cure for AIDS, all of the participants also reported that it was considered discrimination to keep an HIV-positive student from attending school. The majority the students who did not do HIV course felt that HIV infected persons usually appear thin and sickly (57.4 percent) as compared to 2.1 percent of those who did the HIV Course. $60 \%$ of those who did not do the course did not understand that a person could have a negative test for HIV and still be infected. Roughly three-fourths of all respondents agreed that men and women view sexual intercourse differently.

On prevention strategy beliefs, all the respondents demonstrated high levels of knowledge about the protection condoms can provide if used properly and during each sexual encounter. A strong majority also knew that condoms could not be safely used more than one time though 18.8 percent of those who did not do the course thought otherwise. 53.1 percent of the respondents who did not do the course were unaware that Vaseline should not be used as a lubricant with condoms.

Respondents had different views on the modes of transmission. 47.9 percent of the respondents who did not do the course believed that HIV could be transmitted by some types of insects and none from the fourth year respondents. Over 84.6 percent of the sample understood that one could not get HIV from hugging or touching a person who has HIV or AIDS, drinking from the same glass that a person with AIDS has used, eating food prepared by someone who has HIV or AIDS, or wearing clothes that have been worn by another person with HIV. Lastly, on treatment, all the respondents knew that drugs were available to help prolong the life of a person with AIDS and that there is no cure for AIDS through medicine.

\subsection{Case Story A (Female final year student)}

Life is a full of challenges and mysteries. It's full of frustrations due to a lot of unanswered questions. Hence people choose to continue with life by doing programmes that will lessen their burdens to fear. However, answers do not come forth if you have less or no knowledge concerning your difficulties. However, as for me doing an HIV course unveils a number of reasons why people do what they do and live the way they live in terms of altitude of and behaviour.

My admission at the University of Zambia was a way out of terror, sexual abuse, wife battering to mention but a few. Indeed education without transformation of life is invalid. HIV Course is just a course but it guarantees your success in Examination but getting practical ideas, empowerment and constructive elements on changing your altitudes, such that you develop positive thinking towards Voluntary Counselling and Testing (VCT).The lectures at the University of Zambia in this Course transformed my attitude towards getting tested. My fears were suppressed such that I thought that the only way to take care of my predicaments is to go for VCT or Counselling, Care and Testing (CCT) willingly.

After the first two (2) weeks lectures with MR. H. Daka, I took a step to be counselled. He referred me to Mirriam (Counsellor at the Clinic) who counselled and tested me. The results were negative; hence, I did not believe looking at my predicaments. I thought it was still at window level. After three months I was tested negative which led to a fight in my home. I had elusions and reflections on how my husband uses to abuse me sexually. But due to guidance and counselling, I was empowered with knowledge. Surely knowledge is power. Though on separation, I am able to live a positive life because of the knowledge I got from this Course. Really the knowledge acquired from lectures had a great impact of change and awareness on my life. It transformed holistically in that the curriculum followed 
by the lectures is responsive. I was empowered socially, spiritually, morally, practically, physically and academically. Knowledge concerning HIV and AIDS was broadened.

This Course educates students holistically thereby empowering them with desirable skills, values, morals, attitudes and knowledge which can be best utilised for life in a changing global world.I have written these concerns to motivate someone who may be going through similar difficulties.

\subsection{Case Story B (Male final year student)}

Personally I believed in some of the traditional customs though not all but polygamy, I was holding the view that polygamy is good because most men in Zambia are dying in the hands of their wives so that the wives can with children inherit what the man has acquired. But if you have two or three women, there may be a less likelihood of such cases. I was one of the many men that believed that having one sex partner is a sign of weakness. But I have realized in this HIV Course that such beliefs and customs trigger the spread of HIV and probably question myself why I should risky being infected with HIV for fear of the unknown.

This course has greatly opened my mind that especially on casual sex. The opinions and attitudes that we have on things that we usually take as minor lay the secret of our lives and many of our friends who had no chance to have such information as we have got from this course. My personal conviction was that the fight was for those who are infected believing that they were at fought and let them burry themselves, but this course has made a turn round in my life.

Further, I have realized from this Course that if you discriminate either knowingly or unknowingly, you are as good as pushing this person to be depressed and eventually they die earlier because of our attitudes. In most cases, we discriminate directly or indirectly in the way we talk especially when we are in public where some people may be positive or have close relatives, spouses, or friends who are positive. I used to view HIV infected persons as having behaved at least in an immoral way, but this course has helped me to understand that the affections come in various ways though sexual is the most common, being a married person, aim vulnerable and I can equally get it.

With the knowledge I have gained from this course, I have come to realize that in as much as there are campaigns on the spread of HIV, the knowledge we get from these campaigns is too elementally that no matter how much effort the government puts in this fight, the battle may not be won. Before doing this course, I was thinking as though going for Voluntary Counselling and testing (VCT) is just calling for a death sentence on my partner and me. I was one of the many people that when called for $V C T$, the call was judgmental. Sometimes my wife suggested that we be tested as a couple but I was always taking it that she was just being judgmental. The questions that I usually posed were: Did you have sex outside our marriage? Or do you think that I had sex outside our marriage? Such questions were strong enough to defeat her ideas of going for VCT, I always argued with happiness when she tested negative at the anti-natal clinic during her pregnancy that if she is negative, how possible is it that I can be positive. But with the knowledge I have gained in the course, I have realized that there is more that I didn't understand about HIV. And I can openly say that I have become ready to take what I once called a risky to go for VCT with my wife so that whatever the result, we can know our status and know how to live our lives and protect the future of our children.

\subsection{Case Story $\mathrm{C}$ (Female graduate)}

I graduated from the University of Zambia in 2010. Fortunately I was in the class of the first students who benefited from the course that was just introduced that year on HIV and AIDS. Being HIV positive, I thought it was an opportunity for me to learn more. I benefited a lot from the course but among the most notable things I learnt were the following;

\subsubsection{Disclosure}

I learnt that when you are hit with something that you cannot handle it is important to find somebody trustworthy to share with. We were also told that just talking about your status with someone is in itself a part of acceptance. I did not have a problem with accepting my status but I had a problem with sharing. I was coming from a background of being dumped by someone I loved so much because of my status. After that experience, I told myself that I would rather keep the problem to myself than embarrass myself. It indeed went on like that for years. After getting the education of the benefits of 
sharing, I decided to change my mind set and talk to somebody. I started by sharing it with my best friend, at first she was shocked, later she encouraged me and she stood by my side up to date she has been very supportive. Next I decided to talk to my lecturer, Mr Harrison Daka. I decided to do so because I felt I needed to get more data on a personal level. There were some issues that I needed to know that I had little information on. I later little by little opened up to my family members. The information in this Course helped me to open to many who later helped me.

\subsubsection{Opportunistic Diseases}

I obtained a lot of information on some opportunistic diseases that were most common in the people who were HIV positive. Amongst the disease that hit me most was cervical cancer. After learning about the disease and also looking at the signs and symptoms of cervical cancer I realised that I used to experience some of the symptoms. Because of the information I got from the Course and knowing my status, I decided to go for a pap smear. At the UNZA Clinic I was given more information on the disease and was also counselled. When the results came out it was discovered that I actually had cervical cancer. The results hit me so badly that I almost went into depression. I had always associated cancer to death. Again I decided to share my situation with the lecturer of the Course Mr Harrison Daka who was very helpful and supportive. He gave me more literature on the disease and connected me to two doctors who were specifically attached to HIV and AIDS programs. After going through counselling and treatment, I am finally free from cervical cancer.

\subsubsection{Prevention of Mother To Child Transmission (PMTCT)}

During our lectures we were informed that the children that are being born now are hoped to be the windows of hope. This notion came about because of the measures that the government has put in place. Currently all expectant mothers are mandated to HIV testing. When one is found to be positive, immediately they are monitored are put on ARVs so as to make sure that the baby is born HIV negative. After learning all this information, I was motivated to have another child especially that I only had one child who was even in college. After graduation I went to discuss my intentions with the doctor who also said it was alright especially that my CD4 count was on a higher side. As it is now, I'm a mother of a nine months old baby girl. She has so far undergone three tests and the results have been negative. Indeed the children being born today are the windows of hope.

As an individual and especially that I'm HIV positive, I benefited a lot from the course because I was privileged to learn a lot of new stuff. The knowledge I gained has also helped me to change my mind set and somehow I have managed to encourage some colleagues on the importance of VCT. It is a course worth taking.

From the three (3) case stories above, the study showed that the integration of HIV into the curriculum in higher education not does it benefit the students in acquisition of relevant knowledge but also helps them to become agents of positive change. The students' lives became positive and applied the knowledge gained.

\subsection{Lessons from the University of Zambia HIV Course}

The researchers further had Focus Group Discussions (FGDs) with academic staff in other schools of the university. From the FGDs, the study noted various challenges encountered in integrating HIV in the curriculum in higher education. The challenges will be grouped in the following themes, perceptions of staff, infrastructure requirements, gaps in knowledge and implementation.

\subsubsection{Perception of Staff}

Members of staff in programmes that are not in the School of Education and Humanities did not see the need for the integration of HIV in their programmes. They indicated that there was not direct link between their line of programs and the course on HIV. They supposed that if students wanted to learn about HIV, this could be arranged through extra-curricular activities such as those organized by the UNZA special Response Unit. There were students too who agreed withstance. The study noted that students viewed a compulsory course in HIV as a waste of time and financial resources. Their focus was on specific courses that they enrolled for and that which counted to their grades. Lecturers wondered how a course in HIV would be fine tuned to fit in all the programs. 


\subsubsection{Infrastructural Requirements}

Related to the above theme was the issue of infrastructure to accommodate the integration. The general consensus was that there was no physical and virtue space for a specific targeted program in the university. Although they were suggestions that students take the course online in their extra time, it was found that students were already over burdened with course work.

\subsubsection{Gaps in knowledge}

Whilst the integration of the HIV into the university programmes was seen as necessary, the study observed that specific people need to be specially trained to handle such a course. The University did not have specific lecturers that would be resource persons. In line with this suggestion, between 2013 and 2014, some people were identified and trained in various issues relating to HIV.

\subsubsection{Challenges in the Curriculum}

Just as it has been observed in other studies where the challenges of organisation, lack of commitment of administrators, non-trusting relationships between teachers and learners, lack of resources and conflicting goals in the educational system (Visser, 2005), this study was not an exceptional. The following were challenges which hinder the implementation of HIV Course at the University of Zambia:

- Since the course is not compulsory it has translated into having a very limited number of students compared to the university student populace being enrolled in this course leaving other students not participating in the course without access to accurate information about HIV and AIDS within the university.

- The duration of the course is not sufficient enough to develop in entirety the skills aimed at clarifying values and assessing intended behaviour such as fostering positive attitudes towards people with HIV and AIDS and preventive behavioural change as it is a half course (half a year).

- Only two (2) Lecturers are trained to handle the teaching of HIV and AIDS in higher learning institutions. Hence, for the course to be more effective, respondents advocated for the need to involve local HIV and AIDS experts, social scientists and health educators as also advanced by Wood and Pillay (2016).

- In terms of mode of delivery, the course is currently offered through lecture method. There is a need to move beyond university-wide stand-alone modules, compulsory or not, that focus solely on prevention and protection of students' own health. Although needed, they are not sufficient and should be supplemented by discipline specific HIV and AIDS education. Respondents proposed that didactic lectures need to be supported by experiential learning/service learning that allows students to interact with the reality of HIV and AIDS in their own communities/ professions.

- Despite the increase in the knowledge of HIV and AIDS, it was revealed that more learners were still engaged in high-risk sexual behaviour patterns. Respondents suggested that lectures should be supplemented by behavioural interactions such as role plays and clinical interactions with HIV and AIDS patients and counsellors. This way, as evidenced by Zaninovic et al. (2013) in their research "An innovative HIV training program for dental hygiene students" behavioural outcomes are more effective.

In conclusion, this study has shown that integration of HIV and AIDS issues in higher education is hampered by education challenges such as strict timetabling, lack of physical space and knowledge gaps in ever changing knowledge trends on HIV. It has also been established that there is need for constant capacity building of staff for them to effectively teach issues of sexual and reproductive health to combat the spread of HIV and AIDS in Zambia. The study showed that the integration of HIV into the curriculum in higher education does not only benefit the students in acquisition of relevant knowledge but also helps them to become agents of positive change. The students' lives became positive and applied the knowledge gained. The study also showed that students in this course are trained holistically thereby empowering them with desirable skills, values, morals, attitudes and knowledge which can be best utilised for life in a changing global world. 
Integration of HIV and AIDS in Higher Education Curriculum: A Case Study of an HIV Course in the School of Education of the University of Zambia

\section{REFERENCES}

[1] Bonjour, M and Van Der Vlugt, I. (2018). Comprehensive Sexuality Education. Knowledge File. Utrecht, Rutgers.

[2] Chilangwa, B.W. (2010).Zambia's Youth and HIV and AIDS. Lusaka: A Wilfred Bwalya Publications.

[3] Coombe, C. and Kelly, M.J. (2001).Education as a Vehicle for Combating HIV/AIDS. Pro-spects 31(3): 438-445.

[4] Daka, H., James, J. W., Kakupa, K and Mwelwa, K. (2017). The Use of Social Networks in Curbing HIV in Higher Education Institutions: A Case Study of the University of Zambia, World Journal of AIDS, Vol.7 (1), 122 - 137.

[5] Daka, H. (2017). Social Life Skills in the Era of HIV/AIDS among Learners in Learning Institutions, Muka Graphics and Printing Hub, Lusaka. Government of the Republic of Zambia. (2014). Zambia Demographic Health Survey 2013-2014. Lusaka: CSO

[6] Kelly, M. J. (2008). Education for an Africa without AIDS. Nairobi, Kenya: Paulines Publications Africa.

[7] Malungo,R.S.(2006). Report on 2006 Baseline Sexual Behaviour Survey Among University of Zambia Students. For the Vice Chancellor Standing Committee on HIV and AIDS. Lusaka, University of Zambia.

[8] Mbulo Edwin (2014). Livingstone HIV Mortality Drops. The Post, Monday, $24^{\text {th }}$ February page 19

[9] McGinty, S. and K. Mundy.(2009). HIV/AIDS educators: The challenges and issues for Namibian bachelor of education students. Teaching and Teacher Education Vol.25,141-148.

[10] Ministry of Education Science Vocation and Early Childhood Education. (2013). Zambia Education Curriculum Framework. Lusaka. Curriculum Development Centre.

[11] Ministry of Health (MOH). (2015). Zambia Demographic Health Survey. Lusaka, MOH.

[12] Moerschbacher, M; Kato, J and Rutechura, P. (Eds.). (2008).A Holistic Approach to HIVand AIDS in Africa; Nairobi: Paulines Publications Africa.

[13] Moloney, M. (2005).Counselling for HIV/AIDS: The Use of Counselling Skills for HIV/AIDS. Nairobi: Paulines Publications Africa.

[14] Muchiri, J. (2002).HIV/AIDS, Breaking the Silence: A Guide Book for Pastoral Care Givers. Nairobi: Paulines Publications Africa.

[15] Mukuka, L.M., Daka, H. (2018). From Theory to Practice: Young People's Views on Medical Circumcision as an Intervention against HIV/AIDS and other STIs in Kaputa and Mporokoso Districts of Zambia. Journal of Positive Psychology and Counselling, Vol. 1 (2), 78 - 86.

[16] Mukuka, L.M. and Daka, H. (2018). Sustainability and Accessibility of Private Schools in Zambia: Experiences of Low-Cost Private Primary Schools in Lusaka's Peri-Urban Areas. Journal of Positive Psychology and Counselling, Vol. 2 (2), $47-77$.

[17] Nyondo, L. (2013). Sex Education Key to Reducing HIV Prevalence. Zambia Daily Mail, Friday,1st November, page 9.

[18] Panchaud, C; Koegh, S.C; Stillman, M; Awusabo-Asare, K; Motta, A; Sidze, E and Monzon, A.S. (2019). Towards Comprehensive Sexuality Education: Acomparative Analysis of the Policy Environment Surrounding School-Based Sexuality Education in Ghana, Peru, Kenya and Guatemala. Sex Education, Vol. 19 (3), 272-296.

[19] Richards, W. (2002).The AIDS Pandemic. Lusaka: The Stanborough Press Ltd.

[20] Sahu, K. B. (2004). AIDS and Population Education.New Delhi: Sterling Publishers Private Limited.

[21] United Nations Education Scientific and cultural organisation, (UNESCO). (2009). International Technical Guidance on Sexuality Education: An Evidence informed Approach for Schools, Teachers and Health Educators. Vol. 1. Paris: UNESCO

[22] Vanwesenbeeck, I; Westeneng, J; De boer, T; Reinders, J and Van Zorge, R. (2016). Lessons Learnt from a Decade of Implementing Comprehensive Sexuality Education in Resource Poor Settings. The World Starts with me. Sex Education, Vol. 16 (5), 471-486.

[23] Vinogradova, E. (2014). Comprehensive Sexuality Education in Zambian Schools. Why do kids need it? Washington DC: Education Development Centre.

[24] Visser, M.J. (2005).Life Skills Training as HIV/AIDS Preventive Strategy in Secondary Schools: Evaluation of a Large-Scale Implementation Process. Department of Psychology, University of Pretoria.2 (1), 203-16.

[25] Wilmot, D. and Wood, L. (2012). In search of an enabling pedagogy for HIV and AIDS education in initial teacher education. South-African Journal for Higher Education 26(5), 1112-1130. 
[26] Wood L. and Pillay M. (2016). A Review of HIV and AIDS Curricular Responses in the Higher Education Sector: Where Are We Now And What Next? South African Journal of Higher Education. 30 (4), 126-143.

[27] Zaninovic, P;Natto, Z.S; Turner, R.L; Toledo, G.A; Graciela, G; Duran, G.G; Trott, J.R and Rogers, T.(2013). An Innovative HIV Training Program for Dental Hygiene Students. The Journal of Dental Hygiene 87(1), 47-55.

\section{AUTHORS' BIOGRAPHY}

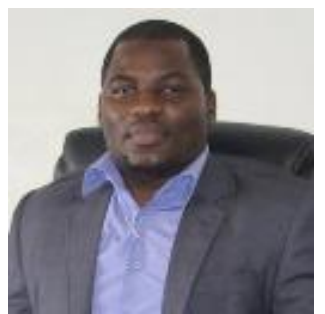

Kapambwe Mwelwa is a Lecturer at the University of Zambia in the Department of Educational Administration and Policy Studies. He holds a Master's Degree in Educational Administration and a Bachelor of Arts with Education Degree from the University of Zambia. He is currently a $\mathrm{PhD}$ candidate in Educational Management at the University of South Africa (UNISA). His current research interests are in Educational Leadership and Management; Higher Education Financing; Skills Development and Employability; Quality, Equity and Access Legal Issues in Educational Management and cross cutting issues in education such as HIV and AIDS.

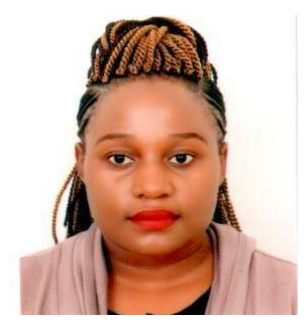

Pilira Tembo is a Holder of Bachelor's Degree in Education with Arts and a Master's Degree in Educational Administration. She is a Lecturer at the University of Zambia in the Department of Educational Administration and Policy Studies housed in the School of Education. Her areas of interest are Educational Financing, School Effectiveness and Technical, Vocational and Entrepreneurship Training.

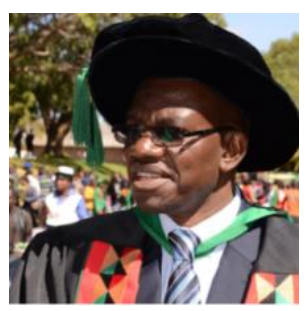

Harrison Daka is a Lecturer in the Department of Educational Administration and Policy studies. He holds a PhD in Health Professions Education (Medical Education), Master's Degree in Educational Administration and a Bachelor of Science with Education Degree from the University of Zambia. He specializes in education, science education, medical education, educational administration and management and anthropology. He also has formal training in leadership, HIV programme delivery and strategies of assessment.

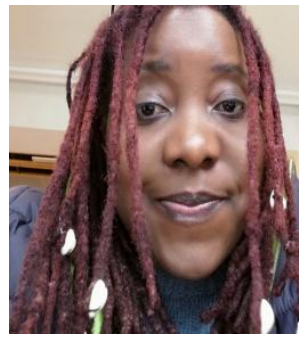

Mukuka Mulenga-Hagane is a Lecturer in the Department of Educational Administration and Policy Studies at The University of Zambia. Her research interests are in International Education and Development with special focus on Education Law. She has experience in academia and developmental research. This includes formal training in leadership and HIV programme delivery. She is currently a Special Research Fellow at the University of Zambia. Her research project explores the prospects of using education law to enhance retention of learners in primary school.

Citation: Harrison Daka, Kapambwe Mwelwa, et.al. "Integration of HIV and AIDS in Higher Education Curriculum: A Case Study of an HIV Course in the School of Education of the University of Zambia". International Journal of Humanities Social Sciences and Education (IJHSSE), vol. 6, no.9, 2019, pp. 83-93. doi: http://dx. doi.org/10.20431/2349-0381.0609009.

Copyright: ( ) 2019 Authors. This is an open-access article distributed under the terms of the Creative Commons Attribution License, which permits unrestricted use, distribution, and reproduction in any medium, provided the original author and source are credited. 